PRINT ISSN 1119-8362

Electronic ISSN 1119-8362
Full-text Available Online at

https://www.ajol.info/index.php/jasem

http://ww.bioline.org.br/ja
J. Appl. Sci. Environ. Manage.

Vol. 24 (1) 37-47 January 2020

\title{
Kinetics and Thermodynamic Study of Corrosion Inhibition of Mild Steel in 1.5M HCl Medium using Cocoa Leaf Extract as Inhibitor
}

\author{
${ }^{* 1 O K E W A L E}, \mathrm{AO} ;{ }^{2}$ ADESINA, OA \\ ${ }^{*}$ Department of Chemical Engineering, Federal University of Petroleum Resources, Effurun, P M. B., 1221, Effurun, Delta State, Nigeria. \\ ${ }^{2}$ Department of Chemical and Petroleum Engineering, Afe - Babalola University Ado - Ekiti, Ekiti State, Nigeria \\ *Corresponding Author Email: Okewale.akindele@fupre.edu.ng
}

\begin{abstract}
This study examined the corrosion inhibition of mild steel in $1.5 \mathrm{M} \mathrm{HCl}$ solution using cocoa leaf extract as an inhibitor. The effect of inhibitor concentrations, kinetics, and time of immersion were undertaken at $30^{\circ} \mathrm{C}$ while the thermodynamic parameters were determined with temperature range of $35^{\circ} \mathrm{C}-55^{\circ} \mathrm{C}$. FTIR result indicated that the actual adsorption of the inhibitor is as a result of donation of single pair of electrons on oxygen to the vacant $\mathrm{d}$ - orbitals of the metal (mild steel) that leads to the formation of complexes on the mild steel surface. The corrosion rate decreased from $1.64 \mathrm{~g} / \mathrm{cm}^{2} \mathrm{hr}$ to $0.09 \mathrm{gm} / \mathrm{cm}^{2} \mathrm{hr}$ in the presence of inhibitor used. However, increased in temperature showed a decreased in inhibition efficiency this resulted to an increase in rate of corrosion. Half - life of the corrosion kinetics ranges from $49.71-53.15 \mathrm{hr}$ which is directly proportional to the inhibitor concentrations. Activation energy Ea, enthalpy $\left(\Delta \mathrm{H}^{\circ}\right)$, and entropy $\left(\Delta S^{\circ}\right)$ calculated showed good interactions. The enthalpy of activation ranges from $63.28 \mathrm{~kJ} / \mathrm{mol}$ to $97.55 \mathrm{~kJ} / \mathrm{mol}$. Rise in activation energy with inhibitor concentration confirmed the physical (physisorption) adsorption mechanism for the corrosion of mild steel surface. Endothermic nature of the corrosion process is ascertained with the positive value of $\Delta \mathrm{H}^{\circ}$ obtained.
\end{abstract}

\section{DOI: $\underline{\text { https://dx.doi.org/10.4314/jasem.v24i1.6 }}$}

Copyright: Copyright $(\underset{C}{ } 2020$ Okewale and Adesina. This is an open access article distributed under the Creative Commons Attribution License (CCL), which permits unrestricted use, distribution, and reproduction in any medium, provided the original work is properly cited.

Dates: Received: 30 November 2019; Revised: 20 December 2019; Accepted: 23 December 2019

Keywords: Gravimetric, thermodynamic, adsorption, activation energy

Corrosion behaviour of steels has received a considerable amount of attention as a result of its industrial importance. Corrosion is the destructive attack of a metal by chemical or electrochemical reaction with its environment. Corrosion is often thought of only in terms of rusting and tarnishing. However, corrosion damage occurs in other ways as well, resulting, for example, in failure by cracking or in loss of strength or ductility. The term corrosion is sometimes also applied to the degradation of plastics, concrete, and wood, but generally refers to metals. The most commonly used metal is iron (usually as steel). Corrosion can cause disastrous damage to metal and alloy structures causing economic consequences in terms of repair, replacement, product losses, safety, and environmental pollution. There are several ways of preventing corrosion and the rates at which it can propagate with a view to improving the lifetime of metallic and alloy materials. Corrosion inhibitors are widely used in industry to reduce the rate corrosion of different metals and alloys that are in contact with aggressive environments (acid solution). Acid solutions are often used in industry for cleaning and pickling of steel structures, processes that are normally accompanied by considerable dissolution of the metal. Corrosion inhibitor is a substance which, when added in small concentration to an environment, effectively reduces the rate of corrosion of a metal exposed to that environment. A useful method to protect metals and alloys in aggressive environments against corrosion is to add some species to the solution in contact with the surface in order to inhibit the corrosion reaction and reduce the rate of corrosion (Oguzie, 2008). Many studies have been carried out to find suitable compounds to use as corrosion inhibitors. Use of inhibitors is one of the most practical and environmentally method for protection of mild steel and metals against corrosion, especially in acid solutions, to prevent unexpected metal dissolution and acid consumption (Sorcha, 2008). Most of these compounds in used as corrosion inhibitors are synthetic chemicals that may be very expensive and hazardous to human, aquatic life and environment at large. It is very important to use cheap, environmentally, and safe to handle compounds for use as corrosion inhibitors. These natural organic compounds are either synthesized or extracted from aromatic herbs, spices, and medicinal plants. Plant extracts are seen as an incredibly rich source of naturally synthesized chemical compounds that can be used as a corrosion inhibitor and are also biodegradable in nature. In very many cases, the 
corrosion inhibitive effect of some of these plants extracts has been attributed to the presence of tannin in their chemical constituents (Loto, 2003). Due to environmental laws and regulations on the use of toxic chemicals, and heavy metal - based inhibitors are being curtailed (Touir et al., 2009). This has led to several attempts on the development of green corrosion inhibitors from plant extracts (Abiola et al, 2007). The inhibitive action of these extracts was attributed to the presence of organic compounds in their chemical constituents and the blocking of the metal surface via adsorption of these organic compounds onto the surface of metal in acidic solutions. Theobroma Cacao belongs to the stercaliaceae family known as cocoa trees. However, mild steel is referred to as low carbon steel which is generally used in chemical and process industries because it is reasonably cheap to produce and has a good toughness, ductility, weldability, and machinability; thus it can be used in different applications such as design of tank, pipelines, and fabrication of reactor vessels fabrication. The inhibitive effect of cocoa leaves (Theobroma Cacao) and kola nut (Cola Acuminata) extracts on the corrosion of mild steel in seawater and marine environment at room temperature was investigated by Urnoru et al., (2006). The results showed that kola nut and cocoa leaves extracts are potential inhibitors of mild steel corrosion.

\section{MATERIALS AND METHODS}

Materials: The cocoa leaves were collected from Ugbomro community located in Effurun, Delta State, Nigeria. Mild steel was procured from accredited iron sheet dealer in Effurun. Macerator apparatus, HANNA model $\mathrm{pH}-211$ ( $\mathrm{pH}$ meter), Genlab oven model Mino/75/f (oven), weighing balance of model (BH $600)$, and beakers, were employed for this corrosion study. Hydrochloric acid, acetone, and ethanol solutions used were of analytical grades and were gotten from a qualified chemical dealer in Effurun, Delta State, Nigeria. Distilled water was procured from the Department of Chemical Engineering Laboratory, Federal University of Petroleum Resources, Effurun Delta, State, Nigeria for sample preparation and solutions.

Pre-treatment of sample and sample characterization: The dried cocoa leaves were used as obtained. This was washed to remove dirt and later sun dried in the oven at $60^{\circ} \mathrm{C}$ for a period of 24 hours to remove inherent moisture in the leaves. Subsequently, this was shredded to a particle size of $0.143 \mu \mathrm{m}$. The sample was stored in a desiccator prior to use.
Fourier Transform Infrared Spectroscopy (FTIR): Cocoa leaf of $0.143 \mu \mathrm{m}$ particle size was examined with FTIR spectroscopy (Buck Scientific model 530) with the range $500-4000 \mathrm{~cm}^{-1}$ (wavelength) to identify the functional group. The background material used in the analysis is potassium bromate $(\mathrm{KBr})$.

$X$ - Ray Fluorescence Analysis $(X-R F)$ : The elemental compositions of the mild steel used were observed with $\mathrm{X}-\mathrm{RF}$ oxford machine.

Analysis of the phytochemical constituents in cocoa leaf extract: Screening of physico - chemical properties and phytochemical constituents of cocoa leaf extract were carried out to identify the active constituents present the cocoa leaf extract. The qualitative and quantitative methods of (Okwu, 2001; Rahilla et al., 1994; Sofowora, 1993; and Herbone 1973) were used for these analyses.

Extraction of cocoa leaf extract: $500 \mathrm{~g}$ cocoa leaf sample was poured in 1L macerator containing $70 \%$ $\mathrm{v} / \mathrm{v}$ of ethanol. The mixture was stirred in the macerator for 4days. The resulting aliquot was subsequently filtered by using Whatman filter paper. The filtrate was transferred to a rotary evaporator at temperature between $54-55^{\circ} \mathrm{C}$ to obtain the extract concentrate. The resultant extract was then stored in an air tight container and kept in a desiccator before used.

Experimental procedure (Weight loss Measurements): The effect of time of immersion and temperature were carried out using weight loss measurement. The effect of temperature was carried out at $308 \mathrm{~K}, 318 \mathrm{~K}$, and $328 \mathrm{~K}$. The corrosion study was carried out using the method described by Nwigbo et al., (2012). The mild steel coupon having dimension of $2 \mathrm{~cm} \times 3 \mathrm{~cm} \times$ $0.12 \mathrm{~cm}$ were polished with abrasive paper, greased to inhibit corrosion, degreased with ether of petroleum and thereafter rinsed with distilled water and dried. The mild steel coupon was suspended with the aid of a thread in $100 \mathrm{~mL}$ beaker that contains $100 \mathrm{ml}$ of $1.5 \mathrm{M} \mathrm{HCl}$ with various concentrations of the inhibitor. At time intervals of 24, 48, 72, 96, and 120 hours, the inhibitor concentrations used are $0.1 \mathrm{~g} / \mathrm{L}, 0.3 \mathrm{~g} / \mathrm{L}$, $0.5 \mathrm{~g} / \mathrm{L}, \quad 0.7 \mathrm{~g} / \mathrm{L}, \quad 0.9 \mathrm{~g} / \mathrm{L}, \quad 1.1 \mathrm{~g} / \mathrm{L}$ and $1.3 \mathrm{~g} / \mathrm{L}$ at temperature of $30^{\circ} \mathrm{C}$. Each coupon after corrosion study was inserted in distilled water and dipped in methanol solution which was scrubbed to remove remaining acids, and residual inhibitor concentration. Thereafter, the mild steel was washed thoroughly with washing liquor, rinsed with distilled water and thereafter dried in acetone before it is reweighed. 
Efficiency of inhibitor determination: The efficiency of corrosion inhibition was obtained using the equation below

$$
\mathbf{E}(\%)=\frac{\mathbf{W}_{\mathbf{0}}-\mathbf{W}_{\mathbf{1}}}{\mathbf{W}_{\mathbf{0}}} \times \mathbf{1 0 0}
$$

Where, $\mathrm{W}_{\mathrm{o}}$ is the loss in weight in uninhibited medium (blank), and $\mathrm{W}_{1}$ is the loss in weight in inhibited medium.

Determination of weight loss: The weight loss of the mild steel coupon was determined using equation 2 below;

Weight loss, $(\mathrm{g})=\mathrm{W}-\mathrm{W}_{\mathrm{i}}$

Where, $\mathrm{W}$ is the initial weight of the mild steel coupon, $\mathrm{W}_{\mathrm{i}}$ is the weight of the mild steel coupon after corrosion study.

Determination of rate of corrosion: The corrosion rate of the mild steel by the inhibitor was calculated using the equation below;

$$
\mathrm{CR}\left(\mathrm{gcm}^{-2} \mathrm{~h}^{-1}\right)=\frac{\Delta \mathbf{w}}{\mathbf{A t}}
$$

Where, $\Delta \mathrm{W}$ is the weight loss in $(\mathrm{g}), \mathrm{A}$ is the area of the Mild steel in $\left(\mathrm{cm}^{2}\right)$, and $\mathrm{t}$ is the exposure time, (hr).

Determination of surface coverage: The degree of surface coverage $(\theta)$ is calculated from the weight loss measurement results using equation (4) below;

$$
\text { Surface coverage }(\theta)=\frac{\text { Wo- } \mathbf{W}}{\mathbf{W o}}
$$

Where; Wo is the weight loss in the absence of the inhibitor, Wi is the weight loss in the presence of the inhibitor.

\section{RESULTS AND DISCUSSION}

Characterization of Cocoa leaf extract: Table 1 shows the presence of tannin, flavonoids, saponin and anthraquinone in the cocoa leaf extract. These phytochemicals has the capacity to enhance the process of corrosion inhibition of mild steel in acidic medium. The presence of these compounds has been reported to promote the corrosion inhibition of mild steel in aggressive acid media (Umoren et al., 2006). This also corroborates the work of (Nwigbo et al., 2012; Prithiba et al., 2014; Owate et al., 2014). Figure1 shows the FTIR of cocoa leaf extract with regions of wavelength $\leq 1500 \mathrm{~cm}^{-1}$ being regarded as the fingerprint region while regions ranging from $1500-3000 \mathrm{~cm}^{-1}$ wavelength are regarded as diagnostic or functional group region. It is this region that indicates the functional group present in the sample.
Table 1 Phytochemical Analysis of Cocoa Leaf Extract

\begin{tabular}{ll}
\hline Chemical constituents & Indicator of Presence \\
\hline Alkaloid & + \\
Terpenoid & - \\
Phenol & + \\
Sterols & - \\
Flavonoid & ++ \\
Cardiac glycoside & + \\
Glycoside & - \\
Tannin & ++ \\
Phytosterol & + \\
Saponins & ++ \\
Anthraquinones & + \\
Reducing sugar & - \\
Steroids & - \\
\hline \multicolumn{2}{c}{$++:$ Abundance, $+:$ Trace, -: Absent }
\end{tabular}

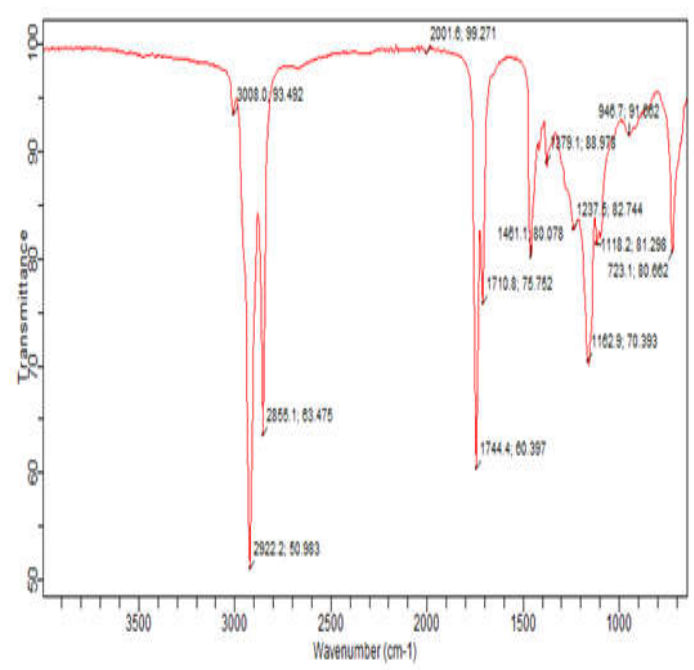

Fig. 1 FTIR Spectroscopy of the cocoa leaf extract

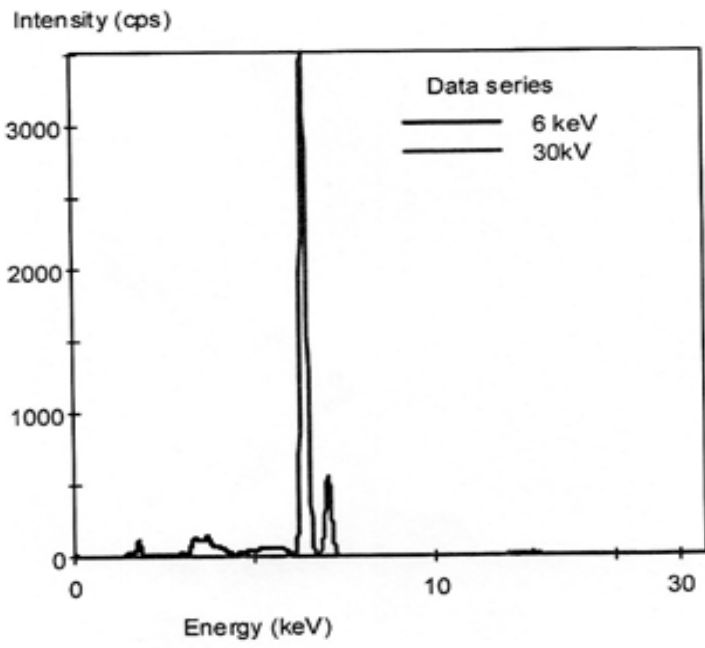

Fig. 2: $\mathrm{X}$ - ray Fluorescence spectra of mild steel sample

The wave number $2922.2 \mathrm{~cm}^{-1}$ gives a sharp shape that shows the presence of $\mathrm{C}-\mathrm{H}$ bond present in the sample. The wavenumber of $2855.1 \mathrm{~cm}^{-1}$ infers the presence of a $\mathrm{C}-\mathrm{H}$ alkyl bond. $1744.4 \mathrm{~cm}^{-1}$ and $1710.4 \mathrm{~cm}^{-1}$ depicts the carbonyl group which is a functional group composed of a carbon atom double- 
bonded to an oxygen atom $\mathrm{C}=\mathrm{O}$ but carbonyl stretch that is saturated with strong conjugation is noticed in $1710.4 \mathrm{~cm}^{-1}$ (Pongpiachan, 2014). $1279.1 \mathrm{~cm}^{-1}$ falls within the wavenumber $\left(1080-1360 \mathrm{~cm}^{-1}\right)$ which gives $\mathrm{C}-\mathrm{N}$ stretch that belongs to amine functional group (Pongpiachan, 2014). The alkene band $(\mathrm{C}-\mathrm{H})$ $\mathrm{sp}^{2}$ functional group is noticed in $3008.01 \mathrm{~cm}^{-1}$. Aromatic overtones of ring bend were seen in wave number $2001.8 \mathrm{~cm}^{-1}$. The presence of aromatic and amine functional groups present in the cocoa leaf extract confirms cocoa leaf extract as good corrosion inhibitors on mild steel.

Table 2 Result of the $X-R F$ Analysis

\begin{tabular}{lll}
\hline Elements & Concentration, $(\mathbf{m g} / \mathbf{k g})$ & Abundance, $\mathbf{( \% )}$ \\
\hline Magnesium & 698.068 & 0.341 \\
Aluminium & 623.737 & 0.304 \\
Silicon & 388.45 & 0.190 \\
Sulphur & 133.15 & 0.065 \\
Chlorine & 63.787 & 0.031 \\
Calcium & 453.855 & 0.221 \\
Titanium & 256.058 & 0.125 \\
Chromium & 136.308 & 0.067 \\
Manganese & 415.195 & 0.203 \\
Iron & 201548.523 & 98.362 \\
Cobalt & 125.519 & 0.061 \\
Bromine & 61.979 & 0.030 \\
\hline
\end{tabular}

Weight loss measurements (Gravimetric measurements): The weight loss of the mild steel metal was determined with various inhibitor concentrations using equation 2 above and plotted in figure 3. It can be seen in figure 3 that there is a reduction in weight loss of the metal coupons in the presence of the inhibitor in comparison to the one without the inhibitor. It is revealed that the weight loss of the coupons decreased as inhibitor concentration is increased with immersion time.

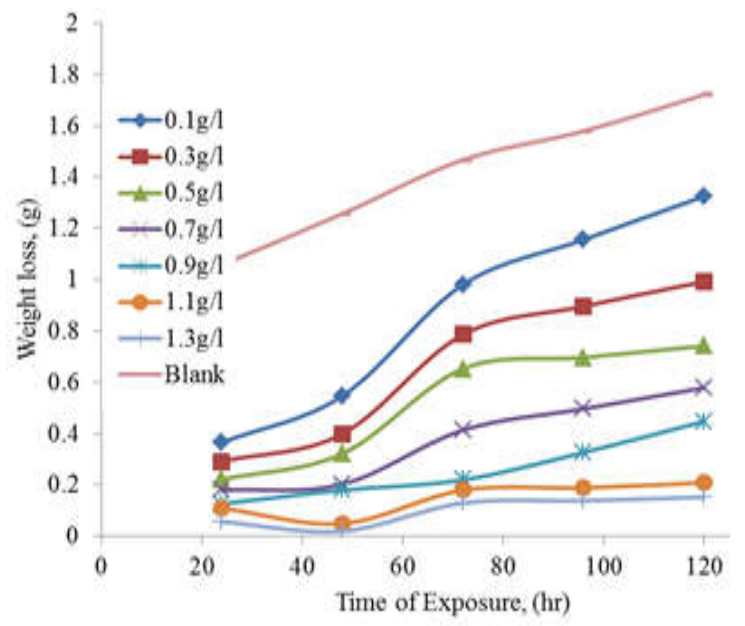

Fig. 3: Weight loss against exposure time

This can be attributed to the fact that with increased in inhibitor concentrations larger number of molecules is adsorbed on the surface of mild steel metal which results in larger coverage of the metal surface by the inhibitor thus making it very difficult for more corrosive attack. The weight loss of mild steel in the absence of cocoa leaf extract inhibitor was much greater compared to the weight loss in the presence of the inhibitor. The inhibition efficiency of cocoa leaf extract was determined with different concentrations of inhibitor by using equation 1 above and the results plotted in figure 4 .

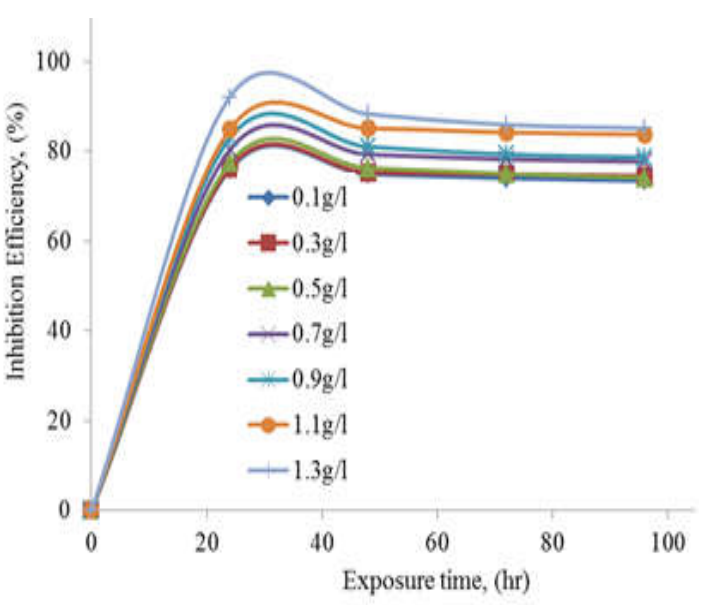

Fig. 4: Inhibition efficiency against exposure time

It has been reported that the inhibitive mechanism of organic compounds is based on their ability to be absorbed at surface of corroding metals. The efficiency of inhibition of the cocoa leaf extract increase with different inhibitor concentrations considered but decreased with time of exposure. The Prolonged time of exposure, long for soaring rate of loading the adsorbed inhibitor on the mild steel metal surface, this results in a constant film that prevents further corrosion of the surface of metal. The reduction in inhibitor efficiency can also be attributed to desorption of the phytochemical constituents from the metal surface (Oguzie et al., 2006). This increased the area that will be available for corrosive attack by the hydrochloric acid. The inhibition efficiency increased at time of exposure of 24 hours but thereafter it is reduced as evidenced in figure 4 . In this work, the maximum inhibition efficiency that was reached is $92.08 \%$ with $1.3 \mathrm{~g} / \mathrm{l}$ of cocoa leaf extract. This can be attributed to the fact that the concentration of inhibitor is highest which can protect the mild steel surface form the aggressive hydrochloric acid environment. At this condition, the surface coverage is the highest with 0.9208 in comparison to others. Large surface areas of mild steel are covered by the film of inhibitor and thus reducing the reaction sites available on the mild steel surface. As a result, this in return giving the least corrosion rate of $0.087 \mathrm{~g} / \mathrm{cm}^{2} \mathrm{hr}$ due to the presence of inhibitor that provide film barrier to corrosive agents. 
High inhibition efficiency observed at 24 hours of immersion suggests that adsorption of cocoa leaf extract inhibitor on the mild steel surface was accomplished within 24hour of immersion; subsequently the mild action of the acid medium was gradually felt other than the inhibitor adsorbed, thus leading to reduced efficiency in inhibition with increased time of exposure. This result corroborate with the works of (Ijuo et al., 2016; Elyn, 2011; Ihebrodike, et al., 2010; Ismail et al., 2011). Similar trends were observed by other researchers. Salah, (2016) observed that inhibition efficiency of the drug inhibitor on mild steel in hydrochloric acid increased by increasing the immersion time up to 6 hour, and thereafter it barely increased. Singh and Quraishi (2010), noticed that the inhibition efficiency of Mannich bases on the corrosion of mild steel in hydrochloric acid solution was found to increase with time up to 12 hour, and thereafter remained almost constant. Figure 5 depicted the rate of corrosion of mild steel in the absence and presence of an inhibitor in the presence of hydrochloric acid. It can be observed that the rate of corrosion of mild steel in the presence of the inhibitor is reduced compared to the one without inhibitor. The corrosion rate increased with time of immersion but decreased with increased in inhibitor concentration.

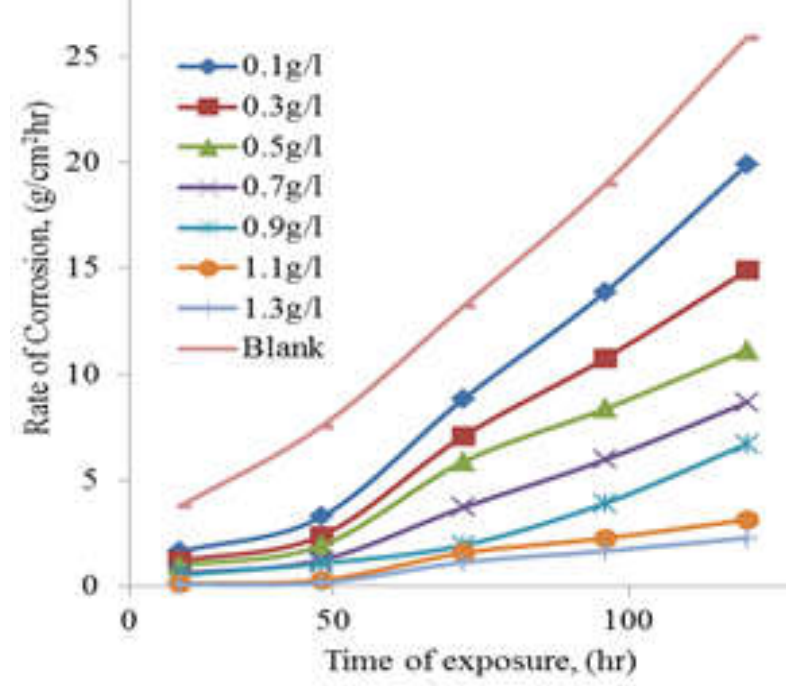

Fig. 5: Rate of corrosion against time of exposure

Kinetics and Thermodynamics of the corrosion process: Rate constant and half-life: The corrosion reaction is a heterogeneous reaction which is composed of anodic reactions at the same or different rate (Olasehinde et al., 2013). The first order kinetics was employed and evaluated using integral method of analysis. This is given by equation 5 below;

$$
-\log (\Delta \mathrm{W})=\frac{\mathbf{K}_{1} \mathbf{t}}{2.303}
$$

Where $\Delta \mathrm{W}$ is the weight loss in (g), $\mathrm{k}_{1}$ is the first order rate constant in $\left(\mathrm{hr}^{-1}\right)$, and $\mathrm{t}$ is the immersion time in (hr). The half - life of this corrosion study was gotten from equation (6), Njoku et al., (2014).

$$
\text { Half-life expression, } \mathrm{t}_{1 / 2}=\frac{0.693}{\mathrm{~K}_{1}}
$$

Figure 6 showed the plot of -log (weight loss) against exposure time in (hours) in the presence and absence of cocoa leaf extracts inhibitor. The rate constant, and half-life parameters are tabulated in Table 2. The plot showed a linear relationship between the slope, $\mathrm{k}$ (the rate constant), thus confirmed a pseudo - first order kinetics on the corrosion of mild steel in hydrochloric acid using cocoa leaf extract as an inhibitor. It was evidenced in table 2 that as the half-life of the kinetic corrosion process increased with inhibitor concentration. The high value of correlation coefficient obtained showed that the experimental value fitted well to the first order kinetics. This result is in conformity with reports of (Ijuo et al., 2016; Olasehinde et al., 2013).

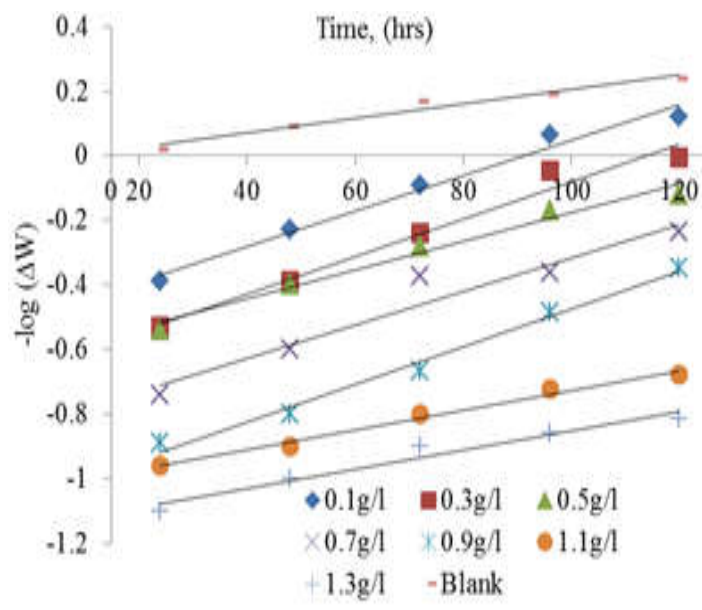

Fig. 6. Kinetics plot of first order reaction

Table 2 Half - life and rate constant parameters at various concentrations of cocoa leaf extract

\begin{tabular}{llll}
\hline Conc. & $\begin{array}{l}\text { Rate constant, } \\
\left.\text { k (hr } \mathbf{~}^{-1}\right)\end{array}$ & $\begin{array}{l}\text { Half }- \text { life, } \\
\text { (hr) }\end{array}$ & $\mathbf{R}^{\mathbf{2}}$ value \\
\hline Blank & 0.013941 & 49.71 & 0.963 \\
$0.1 \mathrm{~g} / 1$ & 0.013841 & 50.07 & 0.9804 \\
$0.3 \mathrm{~g} / 1$ & 0.013573 & 51.06 & 0.975 \\
$0.5 \mathrm{~g} / 1$ & 0.013466 & 51.46 & 0.9762 \\
$0.7 \mathrm{~g} / 1$ & 0.013396 & 51.73 & 0.9383 \\
$0.9 \mathrm{~g} / 1$ & 0.013281 & 52.18 & 0.9883 \\
$1.1 \mathrm{~g} / 1$ & 0.013082 & 52.97 & 0.9863 \\
$1.3 \mathrm{~g} / 1$ & 0.013039 & 53.15 & 0.9863 \\
\hline
\end{tabular}

Effect of temperature on corrosion: The effect of temperature on corrosion inhibition of cocoa leaf extract on mild steel in $1.5 \mathrm{M}$ hydrochloric acid was investigated for 6hours at $0.1 \mathrm{~g} / 1,0.3 \mathrm{~g} / 1$ and $0.5 \mathrm{~g} / 1$ inhibitor concentrations in temperature range $35^{\circ} \mathrm{C}-$ 
$55^{\circ} \mathrm{C}$. Figure 7 gives the effect of temperature on the rate of corrosion process in the absence and presence of inhibitor. The rate of corrosion is higher in medium without inhibitor compared to the one that has inhibitor. As temperature is increased the rate of corrosion also increased due to the fact that the process of corrosion occurred rapidly at higher temperature due to the hot-movement of inhibitor molecules that weakening the adsorption capacity on mild steel surface (Shivakumar and Mohana, 2012; Norzila and Anis, 2015). On the other hand, the inhibition efficiency of the inhibitor decreases with increased in temperature for both absence and presence of inhibitor. This confirmed the physisorption adsorption of the corrosion process that resulted from desorption of adsorbed inhibitor as a result of higher rate of hydrogen evolution due to increased agitation of solution.

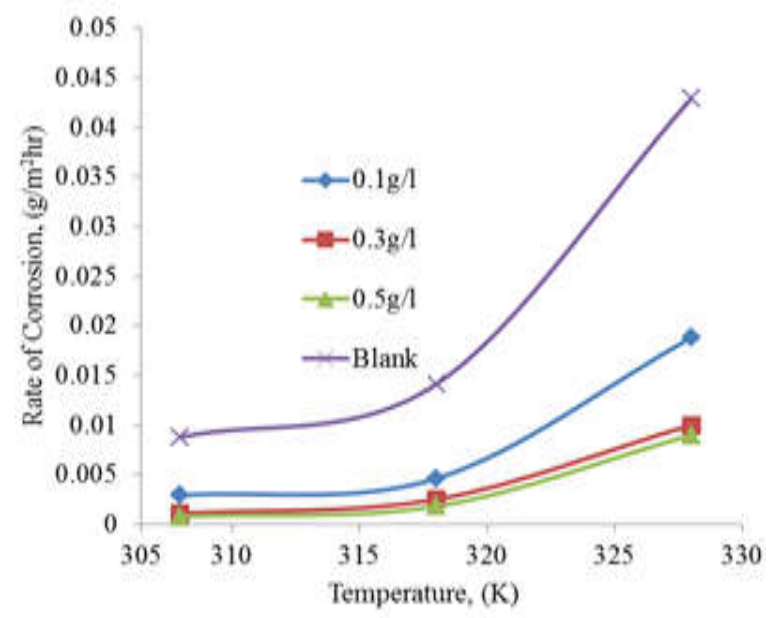

Fig. 7. Effect of Temperature on rate of corrosion of mild steel

Thermodynamic properties such as Activation Energy (Ea), Enthalpy $\left(\Delta \mathrm{H}^{\circ}\right)$ and Entropy of Activation $\left(\Delta \mathrm{S}^{\circ}\right)$ are studied so as to ascertain the mechanism of adsorption process involved in the corrosion process. In other to calculate the thermodynamic parameters like enthalpy $\left(\Delta \mathrm{H}_{\mathrm{ads}}\right)$, and entropy $\left(\Delta \mathrm{S}_{\mathrm{ads}}\right)$ of corrosion process in the presence and absence of cocoa leaf extract inhibitor in hydrochloric acid environment the transition state theory equation given by equation 8 was used (Mouheddin et al., 2018; Ogoke et al., 2009).

$$
\log \left(\frac{C_{R}}{T}\right)=\left[\log \left(\frac{R}{N h}\right)+\frac{\Delta S^{o}}{2.303 R}\right]-\frac{\Delta H^{o}}{2.303 R T}
$$

Where $\mathrm{h}$ is the Planck's constant $\left(6.626176 \times 10^{-34} \mathrm{Js}\right)$, $\mathrm{N}$ is the Avogadro's number, $\left(6.022 \times 10^{23} \mathrm{~mol}^{-1}\right), \mathrm{R}$ is the Universal gas constant $(8.314 \mathrm{~J} / \mathrm{Kmol})$ and $\mathrm{T}$ is the temperature of the medium. The plot of $\log \left(\mathrm{C}_{\mathrm{R}} / \mathrm{T}\right)$ against $1 / \mathrm{T}$ is seen to be linear in Fig. 8 from which $\left(\Delta \mathrm{H}^{\circ}\right)$ and $\left(\Delta \mathrm{S}^{\circ}\right)$ values were deduced from the slopes and intercept of the graph respectively and listed in table 3. Arrhenius equation represented by equation (8) was used to calculate the activation energy $E_{a}$ in the presence and absence of cocoa leaf extract inhibitor.

$$
\log \mathrm{C}_{\mathrm{R}}=\log \mathrm{A}-\frac{\boldsymbol{E}_{\boldsymbol{a}}}{2.303 R T}
$$

Where $C_{R}$ is the rate of corrosion, Ea is the apparent activation energy, $\mathrm{R}$ is the universal gas constant, $\mathrm{T}$ is the absolute temperature, and $\mathrm{A}$ is the frequency factor. The Arrhenius plot of $\log C_{R}$ against reciprocal of absolute temperature $(1 / \mathrm{T})$ is shown in Fig. 9 which gives a straight line with slope of $-\mathrm{Ea} / 2.303 \mathrm{R}$ from which the activation energy of the corrosion process was determined and listed in Table 3 . The enthalpy of activation $\left(\Delta \mathrm{H}^{\circ}\right)$ and the entropy of activation $\left(\Delta \mathrm{S}^{\circ}\right)$ for the corrosion of mild steel in $1.5 \mathrm{M} \mathrm{HCl}$ were obtained from the transition state theory equation expressed as equation (8).

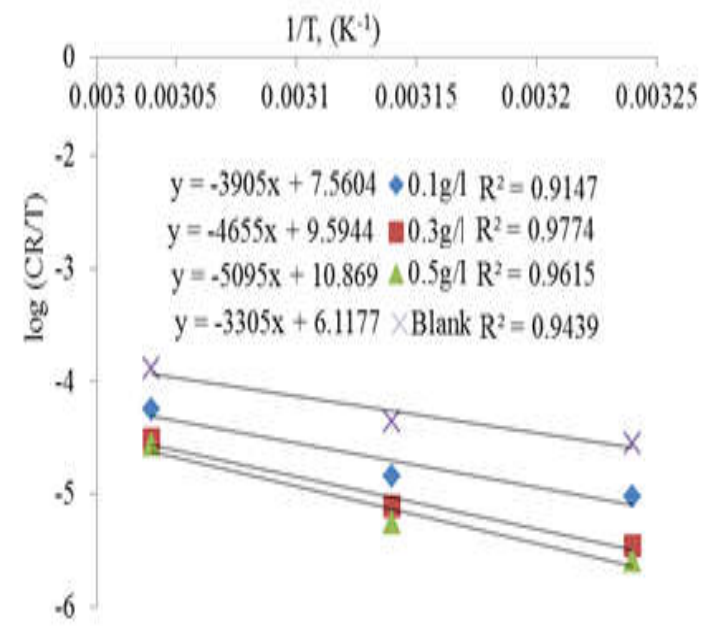

Fig. 8: Transition state for the corrosion of mild steel in absence and presence of inhibitor

Based on Table 3 , the values of corrosion activations increased with inhibitor concentration of cocoa leaf extract. This trend is also consistent with that observed with inhibition efficiency and temperature. The value of $\mathrm{Ea}$ (activation energy) in blank solution is $65.87 \mathrm{~kJ} / \mathrm{mol}$ and rise as concentration of inhibitors are increased from $0.1 \mathrm{~g} / \mathrm{l}(77.45 \mathrm{~kJ} / \mathrm{mol})$ to $0.5 \mathrm{~g} / 1$ $(100.14 \mathrm{~kJ} / \mathrm{mol})$. This is due to the physical barrier produced by the adsorbed molecules on the surface of mild steel. This will increased the least energy required for corrosion reaction to occurs. Additional inhibitors will produce stronger film barriers on the mild steel surface. The trend of increasing Ea values as with inhibitor concentrations has been reported by other researchers on studies on various plant extract such as jujube leaves (Sivakumar and Mohana, 2012), black pepper (Quraishi et al., 2009), sunflower leaves (Cang et al., 2012), and piper nigrum extract (Norzila 
and Anis, 2015). It has been reported that lower Ea value in the presence of inhibitors in comparison to the blank is attributed to chemical adsorption (Solomon et al., 2010; Thirumoolan et al., 2014; Mouheddin et al., 2018). Since, the Ea increased in the presence of inhibitor compared to the blank, the mechanism of corrosion can be ascribed to physical adsorption (physisorption) mechanism. The corrosion reaction will be pushed away on the surface site and occurs at the uncovered parts of mild steel when inhibitors are added in hydrochloric acid solution thus giving a higher value of Ea (Quraishi et al., 2009). In this study, the increasing values of Ea obviously showed a physical adsorption of inhibitor molecules on mild steel surface occurred. Physical adsorption happens due to the electrostatic force between negatively charged metal surface and positive charged of organic species (Norzila and Anis, 2015). The activation entropy $\left(\Delta S^{o}\right)$ in the absence and presence of cocoa leaf extract inhibitor was positive. This can

be interpreted to mean that the activated complex in the rate determining step represents dissociation rather than association step, implying that during the adsorption process, an increase in the degree of orderliness takes place when moving to the activated complex from the reactants. The increased in inhibitor concentration, the more associated is the order of activated complex entangled in the rate determining step of the corrosion reaction. Hence, orderliness is increased as reactants are transformed to activated complex (Nooshabadi and Ghandchi, 2015). The enthalpy of activation $\left(\Delta \mathrm{H}^{\circ}\right)$ values in the presence and absence of inhibitor are positive, close and exhibited the same trend noticed in Ea. From literature, the negative sign of $\left(\Delta \mathrm{H}^{\circ}\right)$ has been clearly associated with an exothermic adsorption process that can either be physisorption or chemisorption or combination of both. However, the positive sign is connected to endothermic adsorption process which is credited to physisorption.

The positive sign of the enthalpy of activation as obtained in the present study reflects the endothermic nature of the process of steel dissolution.

Table 3 Thermodynamic parameters for mild steel in the presence and absence of inhibitor

\begin{tabular}{|c|c|c|c|}
\hline $\begin{array}{l}\text { Concentration } \\
\text { of Inhibitor }\end{array}$ & $\begin{array}{l}\text { Ea } \\
\left(\mathrm{kJ} \mathrm{mol}^{-1}\right)\end{array}$ & $\begin{array}{l}\Delta \mathbf{H}^{\mathbf{0}} \\
\left(\mathrm{kJ} \mathrm{mol}^{-1}\right)\end{array}$ & 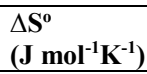 \\
\hline Blank & 65.87 & 63.28 & 297.10 \\
\hline $0.1 \mathrm{~g} / 1$ & 77.45 & 74.77 & 324.72 \\
\hline $0.3 \mathrm{~g} / 1$ & 91.81 & 89.13 & 363.66 \\
\hline $0.5 \mathrm{~g} / 1$ & 100.14 & 97.55 & 388.07 \\
\hline
\end{tabular}

Adsorption isotherm: Three different adsorption isotherms were tested so as to obtain more knowledge about the interface between the mild steel surface and inhibitor. The isotherms tested are Langmuir,
Freundlich, Temkin, and El - Awady adsorption isotherms. The linear regression coefficient of determination $\left(\mathrm{R}^{2}\right)$ was used to adjudge the model that best fit the experimental values. Langmuir relationship is represented by equation (9)

$$
\frac{\mathbf{C}}{\Theta}=\frac{\mathbf{1}}{\mathbf{K}}+\mathbf{C}
$$

Where $\mathrm{K}$ is the equilibrium constant of adsorption ( $\mathrm{M}^{-}$ $\left.{ }^{1}\right)$ which was employed to obtain the Gibb's free energy, $\mathrm{C}$ is the inhibitor concentration, $\mathrm{g} / \mathrm{L}$, and $\mathrm{\theta}$ is the degree of surface coverage (Rajendran et al., 2000; Nnanna et al., 2014). A plot of $\mathrm{C} / \Theta$ against $\mathrm{C}$ as depicted in figure 10 gave a reciprocal of intercept as the adsorption constant. Using the $\mathrm{K}$ value determined from the Langmuir isotherm relationship, the standard Gibb's free energy of adsorption $\Delta \mathrm{G}^{\mathrm{o}}$ ads $(\mathrm{kJ} / \mathrm{mol})$ value at temperature range $35^{\circ} \mathrm{C}-55^{\circ} \mathrm{C}$ was determined according to equation (10) below:

$$
\Delta \mathbf{G}_{\text {ads }}^{\mathrm{o}}=-\operatorname{RT} \ln (55.5 \mathrm{~K}) \quad 10
$$

Where $\mathrm{R}$ is the gas constant $(8.314 \mathrm{~J} / \mathrm{mol}), \mathrm{T}$ is the temperature $(\mathrm{K})$, and 55.5 is the standard molar of water in the solution (Cheng et al., 2007).

Temkin isotherm: This is expressed in equation (11);

$$
\Theta=\frac{1}{f} \ln \left(K_{a d s} C\right)
$$

Equation 11 can be re - written as

$$
\theta=\frac{1}{f} \ln C+\frac{1}{f} \ln K \quad 12
$$

Where $\Theta$ is a linear function of $\ln \mathrm{C}$ (Nnanna et al., $2009), \mathrm{K}$ is the equilibrium constant of adsorption, $(\mathrm{L} / \mathrm{g}), \mathrm{C}$ is the inhibitor concentration, $(\mathrm{g} / \mathrm{L})$, and $\mathrm{f}$ is a coefficient of inhomogeneity connected with the range of inhomogeneity $\mathrm{C}$ by equation 13 .

$$
\mathrm{f}=\mathrm{C} / \mathrm{RT} \quad 13
$$

A plot of $\Theta$ against $\ln C$ gives a straight line as indicated in figure 11, if Temkin isotherm is follow. Freundlich isotherm. The fitting of non - ideal system can be done sometimes by fitting the experimental data to Freundlich adsorption isotherm as seen in figure 12 (Yaro and Khadom, 2008). This is expressed in equation 14 :

$$
\boldsymbol{\theta}=\mathbf{K C}^{\mathbf{n}}
$$

Equation 14 can be re - written as

$$
\ln \theta=\ln K+n \ln C \quad 15
$$


A plot of $\ln \Theta$ against $\ln C$ should give a straight line. Where $\Theta$ is the degree of surface coverage, $C$ is the inhibitor concentration, $\mathrm{g} / \mathrm{L}, \mathrm{K}$ is the adsorption constant which is a measure of adsorption capacity, $(\mathrm{L} / \mathrm{g})$, and $\mathrm{n}$ is the positive constant called the Freundlich exponent which talks about the intensity of adsorption process on the mild steel surface.

El-Awady isotherm: This model is also referred to as the kinetic/thermodynamic model and is written as follows;

$$
\log \left(\frac{\theta}{1-\theta}\right)=\log \mathrm{k}+\mathrm{y} \log \mathrm{C}
$$

16

Where y represents the number of inhibitor molecules occupying one active site of the metal surface, $\Theta$ is the degree of surface coverage, $\mathrm{C}$ is the inhibitor concentration, $\mathrm{g} / \mathrm{L}$.

A plot of $\log (\Theta / 1-\Theta)$ against $\log \mathrm{C}$ as shown in figure 13 can be used to determine the associated parameters such as the reciprocal of $y$ which is used to describe the number of active sites on the surface occupied by one molecule of the inhibitor. It can be related to the binding constant, $\mathrm{B}$, according to equation (17).

$$
\mathrm{B}=\mathrm{k}^{1 / \mathrm{y}}
$$

When $1 / y>1$, each inhibitor molecule is believed to occupying more than one active site on the metal surface and vice - versa (Fouda and Ellithy, 2009).

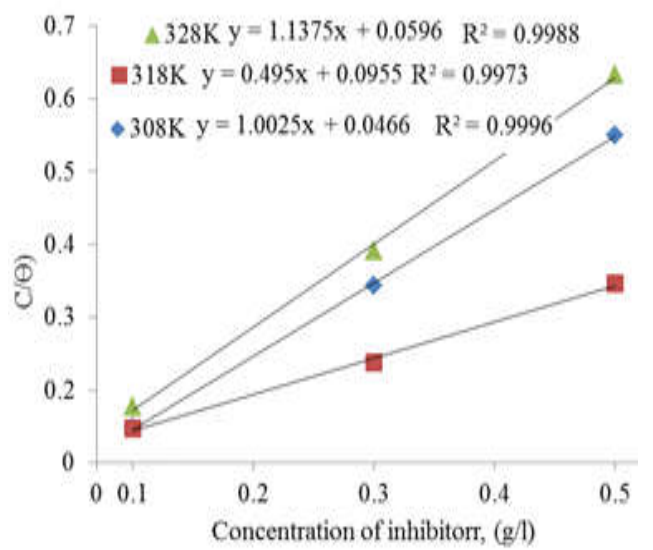

Fig 9. Langmuir isotherm for adsorption of cocoa leaf extract inhibitor on mild steel surface

Based on Table 4-7, the $\mathrm{R}^{2}$ values obtained from the linear regression of the experimental data showed they are close to unity which suggested that the adsorption of cocoa leaf extract molecules onto the surface of mild steel is strongly fitted to Langmuir, and $\mathrm{El}-$ Awady isotherms.

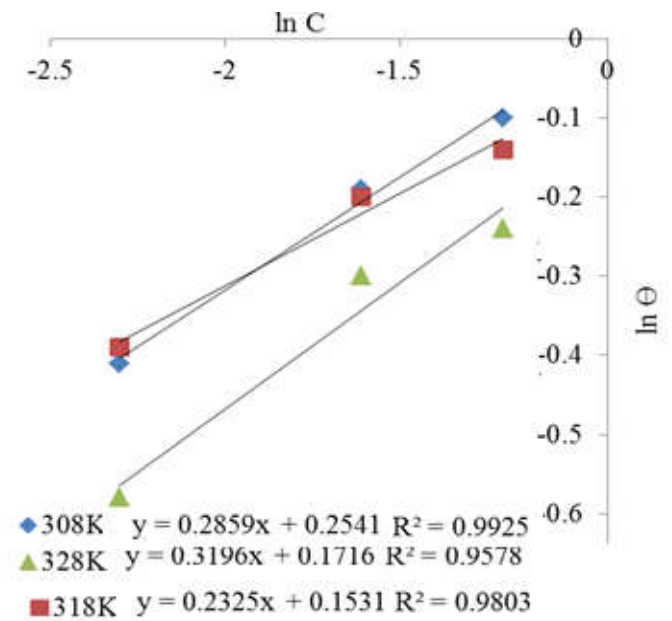

Fig 10. Freundlich isotherm for adsorption of cocoa leaf extract inhibitor on mild steel surface

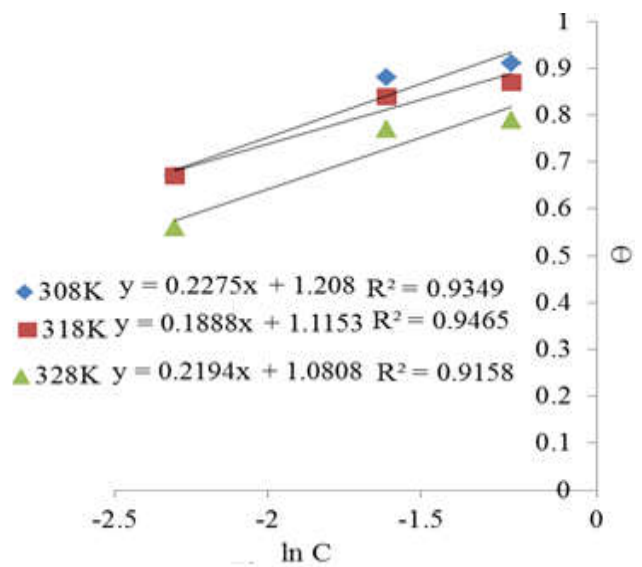

Fig 11. Tempkin isotherm for adsorption of cocoa leaf extract inhibitor on mild steel surface

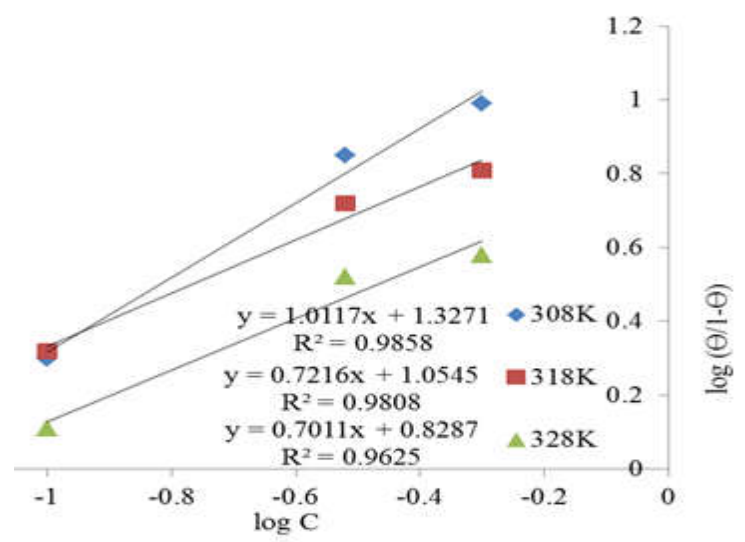

Fig 12. El-Awady isotherm for adsorption of cocoa leaf extract inhibitor on mild steel surface

Though, the Langmuir plot is linear with good correlation coefficient values, the slopes are greater than 1 this indicated a variation from an ideal Langmuir adsorption equation (Mouheddin et al., 2018; Solomon et al., 2010). This implied that there is 
an interaction between surface of mild steel metal and species of adsorbed inhibitor molecules. The value of intensity adsorption shown in Table 5 is lesser than unity which indicated moderate adsorption. Table 6 showed the Temkin isotherm model parameters where the effect of indirect adsorbate (inhibitor)/adsorbate (inhibitor) interactions with the metal surface on the adsorption process was confirmed. The $\Delta \mathrm{G}^{\mathrm{o}}$ ads values obtained ascribed chemisorption nature of Temkin isotherm. From Table 7, the value of reciprocal of $y$ gotten for $0.1 \mathrm{~g} / \mathrm{L}$ of inhibitor concentration at $308 \mathrm{~K}$ temperature is less than unity; this showed that each molecule of the inhibitor occupied less than one active site on the metal surface. The value of $1 / y$ obtained for $0.3 \mathrm{~g} / \mathrm{L}$, and $0.5 \mathrm{~g} / \mathrm{L}$ inhibitor concentration at $318 \mathrm{~K}$ and $328 \mathrm{~K}$ respectively is greater than 1 which showed each molecule of the inhibitor is believed to occupy more than one active site on the metal surface (Fouda and Ellithy, 2009). The calculated values of $\Delta \mathrm{G}^{\mathrm{o}}$ ads listed in Tables 4, 5, and 7 are in the range $-10.93-18.64 \mathrm{~kJ}$ $\mathrm{mol}^{-1}$.

Table 4 Langmuir Adsorption Isotherms Parameters

\begin{tabular}{llll}
\hline $\begin{array}{l}\text { Temp., } \\
(\mathrm{K})\end{array}$ & $\begin{array}{l}\mathrm{K}_{\mathrm{ads}} \\
(\mathrm{L} / \mathrm{g})\end{array}$ & $\mathrm{R}^{2}$ & $\begin{array}{l}\Delta \mathrm{G} \\
\left(\mathrm{KJmol}^{-1}\right)\end{array}$ \\
\hline 308 & 21.46 & 0.9996 & -18.14 \\
318 & 10.47 & 0.9973 & -16.83 \\
328 & 16.78 & 0.9988 & -18.64 \\
\hline
\end{tabular}

Table 5 Freundlich Adsorption Isotherm Parameters

\begin{tabular}{lllll}
\hline $\begin{array}{l}\text { Temp. } \\
(\mathrm{K})\end{array}$ & $\begin{array}{l}\mathrm{K}_{\text {ads }} \\
(\mathrm{L} / \mathrm{g})\end{array}$ & $\mathrm{R}^{2}$ & $\mathrm{n}$ & $\begin{array}{l}\Delta \mathrm{G} \\
\left(\mathrm{KJmol}^{-1}\right)\end{array}$ \\
\hline 308 & 1.289 & 0.9925 & 0.2859 & -10.93 \\
318 & 1.165 & 0.9803 & 0.2325 & -11.02 \\
328 & 1.187 & 0.9578 & 0.3196 & -11.42 \\
\hline
\end{tabular}

Table 6 Temkin Adsorption Isotherm Parameters

\begin{tabular}{lllll}
\hline $\begin{array}{l}\text { Temp, } \\
(\mathrm{K})\end{array}$ & $\begin{array}{l}\mathrm{K}_{\mathrm{ads}} \\
(\mathrm{L} / \mathrm{g})\end{array}$ & $\mathrm{R}^{2}$ & $\mathrm{f}$ & $\begin{array}{l}\Delta \mathrm{G} \\
\left(\mathrm{KJmol}^{-1}\right)\end{array}$ \\
\hline 308 & 202.42 & 0.9349 & 4.396 & -23.88 \\
318 & 460.73 & 0.9465 & 5.319 & -26.83 \\
328 & 137.72 & 0.9158 & 4.557 & -24.38 \\
\hline
\end{tabular}

Table $7 \mathrm{El}$ - Awady Adsorption Isotherm Parameters

\begin{tabular}{llllll}
\multicolumn{7}{c}{ Table 7 El - Awady Adsorption Isotherm Parameters } \\
\hline $\begin{array}{l}\text { Temp } \\
(\mathrm{K})\end{array}$ & $\begin{array}{l}\mathrm{K}_{\mathrm{ads}} \\
(\mathrm{L} / \mathrm{g})\end{array}$ & $\mathrm{R}^{2}$ & $\mathrm{y}$ & $\mathrm{B}$ & $\begin{array}{l}\Delta \mathrm{G} \\
\left(\mathrm{KJmol}^{-1}\right)\end{array}$ \\
\hline 308 & 21.24 & 0.9858 & 1.0117 & 20.50 & -18.11 \\
318 & 11.34 & 0.9808 & 0.7216 & 28.94 & -17.04 \\
328 & 6.74 & 0.9625 & 0.7011 & 15.19 & -16.16 \\
\hline
\end{tabular}

These value less negative than $-20 \mathrm{kJmol}^{-1}$, from literature value of $\Delta \mathrm{G}_{\text {ads }}^{\mathrm{o}}=-20 \mathrm{kJmol}^{-1}$ or less suggested physisorption that involved electrostatic interaction between charged molecules whereas those in the order of -21 to $-40 \mathrm{~kJ} \mathrm{~mol}^{-1}$ or more is taken as chemisorption that involved transfer or sharing of charge from the inhibitor to the surface of metal to form a kind of co-ordinate bond (Yaro and Khadom, 2008; Roy et al., 2014). From the values of $\Delta \mathrm{G}^{\mathrm{o}}$ ads obtained in this work, it can be inferred that mechanisms of adsorption of cocoa leaf extract on mild steel surface might involve two types of interface namely physisorption and chemisorption. It can be thought that adsorption occurred first in the metal surface due to physisorption as a result of effective adsorption of molecules of water on the mild steel surface. The unused part of the water molecules adsorbed on the metal surface water is complemented by a chemical interaction between the metal surface, and the inhibitor that showed chemisorption adsorption process.

Conclusion: In the present work, cocoa leaf was extracted and characterized using phytochemical analysis, and FTIR while the mild steel was characterized using the $\mathrm{X}-\mathrm{RF}$ for elemental compositions. FTIR result indicated that the actual adsorption of the inhibitor is as a result of donation of single pair of electrons on oxygen to the vacant $d-$ orbitals of the metal that leads to the formation of complexes on the metal surface. Kinetics and thermodynamic studies were carried out to estimate the binding/adsorption mechanism of the molecules of inhibitor onto the surface of the mild steel. It was observed that the maximum inhibition efficiency of $92.08 \%$ was attained when the inhibitor concentration is $1.3 \mathrm{~g} / 1$ at 24 hours time of immersion due to higher surface coverage of the extract on mild steel surface (0.9208). However, the lowest inhibition efficiency of $72.63 \%$ was recorded at $0.1 \mathrm{~g} / 1$ which is the lowest concentration of inhibitor used due to lower surface coverage value of 0.7263 . Corrosion inhibition of the cocoa leaf extract on mild steel surface occurred by physical adsorption mechanism. This was proved with the values of activation energy that was obtained in inhibited medium which is higher than in the blank solution.

\section{REFERENCES}

Abiola,OK; Ofarka, NC; Ebeneso, EE; Nwinuka, NM (2007). Eco-friendly corrosion inhibitors: Inhibitive action of Delonix regia extract for the corrosion of alluminim in acidic medium. AntiCorrosion Journal. 54: 219 - 224

Cang, H; Shi, W; Shao, J; Xu, Q; (2012). Study of Stevia rebaudiana leaves as green corrosion inhibitor for mild steel in sulphuric acid by electrochemical techniques, International Journal of Electro. Sci. 7(4):3726-36.

Cheng, S; Liu, CT; Chang, X; Yin, Y; (2007). Carboxymenthylchitosan as an eco-friendly inhibitor for mild steel in $1 \mathrm{M} \mathrm{HCl}$. Mater. Letter. $61: 14-15$. 
Elyn, WAW; (2011). Corrosion inhibition of mild steel in $1 \mathrm{M} \mathrm{HCl}$ solution by Xylopia Ferruginea leaves from different extract and partitions. Int. $J$. Electrochem. Sci., 6:2998-3016.

Fouda, AS; Ellithy, AS; (2009). Inhibition effect of 4 - phenyl thiazole derivatives on corrosion of 304L stainless steel in $\mathrm{HCl}$ solution, Corrosion Sci., 51. $868-875$

Ihebrodike, MM; Anthony, AU; Kelechukwu, BO; Alozie, GA; (2010). The inhibition effect of Solanummelongena L, leaf extract on the corrosion of aluminium in tetraoxosulphate (VI) acid, Afr. J. Pure Appl. Chem. 4:158-165

Ijuo, GA; Chahul, HF; Eneji, IS; (2016). Corrosion inhibition and adsorption behaviour of Lonchocarpus laxiflorus extract on mild steel in hydrochloric acid. Ew. J. Chem. Kine. 1:21-30

Ismail, M; Abdulrahman, AS; Hussain, MS; (2011). Solid waste as environmental benign corrosion inhibitors in acid medium. Int. J. Engg. Sci. Technol. 3(2):1742 - 748

Loto, CA; (2003). The Effect of Bitter Leaf Extract on the Inhibition of Mild Steel in $\mathrm{HCl}$ and $\mathrm{H}_{2} \mathrm{SO}_{4}$. Corrosion Prevention Control, 50 (1):43-49

Mouheddin, T; Alhaffar, Saviour, AU; Ime, BO; Shaikh, AA; (2018). Isoxazolidine derivatives as corrosion inhibitors for low carbon steel in $\mathrm{HCl}$ solution: experimental, theoretical and effect of KI studies, Royal Society of Chemistry, 8: 1764 1776

Njoku, VO; Oguzie, EE; Obi, C; Ayuk, AA; (2014). Baphia nitida Leaves extract as a Green Corrosion Inhibitor for the Corrosion of Mild Steel in Acidic Media. Advances in Chemistry, 2014:1 - 10

Nnanna, LA; Uchendu, KO; Nwosu, FO; Ihekoronye, U; Eti, EP; (2014). Gmelina Arborea Bark Extracts as a Corrosion Inhibitor for mild steel in an acidic environment, Inter. Jour. of Mater. and Chem., 4(2):34 - 39.

Nooshabadi, MS; Ghandchi, MS; (2015). Metall. Mater. Trans. A, 46, 5139-5148

Norzila, M; Anis, SI; (2015). Thermodynamic Study of Corrosion Inhibition of Mild Steel in Corrosive Medium by Piper nigrum Extract. Indian Journal of Science and Technology. (1) 8 (17):1 - 6
Nwigbo, SC; Okafor, VN; Okewale, AO; (2012). Comparative Study of Elaeis Guiniensis Exudates (Palm Wine) as a Corrosion Inhibitor for Mild Steel in acidic and Basic Solutions. Research Journal of Applied Science Engineering and Technology, 4(9):1035 - 1039

Ogoke, EC; Odoemelam, SA; Ita, BI; Eddy, NO; (2009). Adsorption and inhibitive properties of clarithromycin for the corrosion of zinc in 0.01 to $0.05 \mathrm{M} \mathrm{H}_{2} \mathrm{SO}_{4}$, Port, Electrochim. Acta. 27:713 724

Oguzie, EE; (2008), Corrosion inhibitive effect and adsorption behaviour of Hibiscus sabdariffa on mild steel in acidic media. Portugaliae Electrochimica Acta. 26 (3):303-314

Oguzie, EE; Onuchukwu, AI; Okafor, PC; Ebenso, EE; (2006). Corrosion Inhibition and adsorption behaviour of Occimum basiclicum extract on aluminium. Pigment and Resin Technol., 35: 63 70

Okwu, DE; (2001). Evaluation of the Chemical Composition of indigenous species and flavouring agents, Global Journal of Pure and Applied Science. 7(3):455 - 459

Olasehinde, EF; Olusegun, SJ; Adesina, AS; Omogbehin, SA; Momoh-Yahayah, H; (2013). Inhibitory action of Nicotiana tobacum extracts on the corrosion of mild steel in $\mathrm{HCl}$ : adsorption and thermodynamic study. Nat. Sci. 11:83-90

Owate, IO; Nwadiuko, OC; Dike, II; Isu, JO; Nnanna, LA; (2014). Inhibition of Mild Steel Corrosion by Aspilia africana in Acidic Solution, American Journal of Materials Science, 4(3): 144-149

Prithiba, A; Leelavathi, S; Rajalakshmi, R; (2014). Application of Natural Products as Corrosion Inhibitors in Different Steel and Media, Chemical Science Review and Letters, 3:177 - 187

Pongpiachan, S; (2014). FTIR spectra of organic functional group compositions in $\mathrm{PM}_{2.5}$ collected at Chiang Maicity, Thailand during the Haze episode in March 2012, Journal of Applied Sciences. 14 (22): 2967 - 2977

Quraishi, MA; Singh, A; Singh, VK; Yadav, DK; Singh, AK; (2010). Green Approach to Corrosion Inhibition of Mild Steel in Hydrochloric Acid and Sulphuric Acid Solutions by the Extract of 
Murrayakoenigii Leaves. Materials Chemistry and Physics, 122 (1):114 - 122

Rahilla, TN; Rukh, S; Ziaidi, AA; (1994). Phytochemical Screening of Medicinal Plants belonging to Euphoribiaceae Pak. Veterinary Journal. 14(1994): 160 - 2

Rajendran, S; Joany, MR; Apparao, BV; Palaniswamy, N; (2000). Synergistic effect of calcium gluconate and $\mathrm{Zn}^{2}$ on the inhibition of corrosion of mild steel in neutral aqueous environment, Trans. SAEST. 35(3, 4):113

Roy, P; Pal, A.; Sukul, D; (2014). Origin of the synergestic effect between polysaccharide and thiourea towards adsorption and corrosion inhibition for mild steel in sulphuric acid. $R S C$ Adv. 4: 10607-10613

Salah, HA; (2016); Modeling of Corrosion Kinetics of Mild Steel in Hydrochloric Acid in the Presence and Absence of a Drug Inhibitor. Port. Electrochim. Acta 34 (6)

Shivakumar, SS; Mohana, KNS; (2012). Ziziphus mauritiana leaves extract as corrosion inhibitor for mild steel in sulphuric acid and hydrochloric acid solution. European Journal of Chemistry. $3(4): 426-32$

Singh, AK; Quraishi, MA; (2010). Effect of cefazolin on the Corrosion of mild steel in $\mathrm{HCl}$ solution. Corros. Sci., 52:152 - 160
Sofowara, A; (1993); Medicinal Plants and Traditional Medicine in Africa, Ibadan, Nigeria, Spectrum Book Ltd., 289

Solomon, MM; Umoren, SA; Udousoro, II; Udoh, A P; (2010), Inhibitive and adsorption behaviour of carboxymethyl cellulose onmild steel corrosion in sulphuric acid solution. Corros. Sci., 52:13171325

Thirumoolan, D; Katkar, VA; Gunasekaran, G; Kanai, T; Basha, KA; (2014). Hyperbranched poly(cyanurateamine): A new corrosion inhibitor for mild steel in hydrochloric acid medium. Prog. Org. Coat. 77:1253-1263

Touir, R; Dkhireche, N; EbnTouhami, M; Lakhrissi, M; Lakhrissi, B; Sfaira, M; (2009). Corrosion and scale processes and their inhibition in simulated cooling water systems by monosaccharides derivatives Part I: EIS study. Desalination. 249(3):922-928

Umoru, LE; Fawehinmi, IA; Fasasi, AY; (2006). Investigation of the inhibitive influence of theobroma cacao and cola acuminata leaves extracts on the corrosion of a mild steel in sea water, Journal of Applied Sciences Research. 2(4):200 - 204

Yaro, A. S., and Khadom, A. A., (2008), Evaluation of the performance of some chemical inhibitors on corrosion inhibition of copper in acid media, Journal of Engineering, 2(14), 2350 - 2362 